\title{
AUTOTUNING OF PID CONTROLLER FOR ROBOT ARM AND MAGNET LEVITATION PLANT
}

\author{
C.B.Kadu ${ }^{1}$, S.B.Bhusal ${ }^{2}$, S.B Lukare $^{3}$ \\ ${ }^{1}$ Asscoiate Professor, Department of Instrumentation \& control Engineering, Pravara Rural Engineering College, \\ Loni SavitribaPhule Pune University, Maharashtra India \\ ${ }^{2}$ M.E, Department of Instrumentation \& control Engineering, Pravara Rural Engineering College, Loni SavitribaPhule \\ Pune University, Maharashtra India \\ ${ }^{3}$ M.E, Department of Instrumentation \& control Engineering, Pravara Rural Engineering College, Loni SavitribaPhule \\ Pune University, Maharashtra India
}

\begin{abstract}
One of the most essential work of the control engineer is tuning of controller. Majority of the controller used in industry are of the PID type. An auto tuning is one of the method of controller tuning in which tuning of the parameters of controller is done automatically and possibly, without any user interaction expect from initiating the operation. Present study emphasis on the relay based auto tuning of PID controller. An auto-tuning method is implemented based on a relay experiment to determine the ultimate gain and the ultimate period, with which the PID parameters are obtained using the Ziegler-Nichols tuning rules. An auto tuning of robot arm model and magnet levitation model are carried out. Performance of relay based auto tuning on the basis of integral square error is better than artificial neural network.
\end{abstract}

Keywords: Relay auto tuning, PID, FOPDT, SOPDT, Integral square error.

\section{INTRODUCTION}

Auto tuning of PID controller is studied in this paper. A large industrial process may have hundreds of these controllers. They have to be tuned individually to match the process dynamics in order to provide good and robust control performance in process industry, Most of the times it is difficult to tune the PID controller. Tuning of control loop is the adjustment of its control parameters (proportional gain, integral gain, derivative gain) to the optimum values. For the desired control response stability is a basic requirement. There are different methods of tuning. All are manually tuned; it is very similar to trial and error method. All this methods are very tedious and time consuming; the resultant system performance mainly depends on the experience and the process knowledge of the engineer. To overcome all the drawbacks of the manual tuning methods, auto tuning of PID controllers is preferred. "Auto tuning is an appropriate alternative to the continuous cycling method". For relay auto tuning of PID controller relay feedback is used. Astrom[1]. have use of an ideal (on-off) relay to generate a sustained oscillation of the controlled variable and to get the ultimate gain $\left(k_{u}\right)$ and the ultimate method a simple experimental test is used to determine $k_{u}$ and $p_{u}$. For this test, the PID controller is temporarily replaced by a relay which exhibits a sustained oscillation that is the characteristic of on-off control. Ideal relay is used to generate sustained oscillation of control Variable and to get the ultimate gain $\left(k_{u}\right)$ and ultimate period $\left(p_{u}\right)$ directly from relay experiment frequency $\left(w_{u}\right)$ directly from the relay experiment. Relay based auto tuning is the one of simplest and robust auto tuning technique for process controllers. In relay auto tuning

$$
\begin{aligned}
& k_{u}=\frac{4 h}{\pi a} \\
& w_{u}=\frac{2 \pi}{p_{u}}
\end{aligned}
$$

\subsection{Improved Relay Tuning Method}

Relay consists of many sinusoidal waves of odd multiple of fundamental frequency and amplitude. This method incorporating the higher order harmonics explains the error in ultimate gain calculation [2].

$$
k_{u}=1.29(N)^{0.1}\left(\frac{h}{a}\right)
$$

Here, $N=$ number of harmonics, $k_{u}=$ ultimate gain, $h$ =relay height, $a$ =relay amplitude. At the time of performing experiment we can assumed various number of harmonics.

\subsection{Taguchi's Method}

Taguchi method involves reducing the variation in a process through robust design of experiments. The overall objective of this method is to produce high quality product at low cost 
to the manufacture. Taguchi developed a method for designing experiments to investigate how different parameters affect the mean and variance of a process performance characteristic that defines how well the process is functioning. Taguchi method treats the optimization problem. The main aim of this method is to minimize variations in output even though noise is present in the process. The process then said to have become robust.

$$
S N R=-10 \log \left(\frac{1}{n} \sum_{i=1}^{n} y_{i}^{2}\right)
$$

Basic information as well as training procedure of artificial neural network is explained [3]. Relay parameters are considered as design variables. The error in ultimate gain ( $k_{u}$ ) has been considered as performance functions to represent the performance of the design. The mean and the variance are combined into a single performance measure known as the Signal-to-Noise $(\mathrm{S} / \mathrm{N})$ ratio. The process design phase involves deciding the best value of the control factor. The optimum values obtained for relay parameters are used for calculation of ultimate gain $\left(k_{u}\right)$ and consequently the optimum PID parameters. Taguchi method is used for robust analysis of the system. [4]. the procedure of relay auto tuning implementation is explained in MATLAB Simulink.

\section{MODEL IDENTIFICATION}

\subsection{Artificial Neural Network}

Artificial neural network have emerged from the studies of how brain performs. The human brain is made up of many millions of individual processing elements, called neurons that are highly interconnected. Information from the outputs of the other neurons, in the form of electrical impulses, is received by the cell at connections called synapses. The synapses connect to the cell inputs or space dendrites, and the single output of the neuron appears at the axons. An electrical pulse is sent down the axon when the total input stimuli from all of the dendrites exceed a certain threshold. Artificial neural networks are made up of simplified individual models of the biological neuron that are connected together to form a network. Information is stored in the network often in the form of different connection strengths, or weights, associated with the synapses in the artificial neuron models. Some of the various properties of neural networks are:

- Capability of learning information by example. The learning mechanism is often achieved by appropriate adjustment of the weights in the synapses of the artificial neuron models.

- Robustness to noisy data that occurs in real world application.

- $\quad$ Ability to generalize the new inputs.

- Fault tolerance.
A neural network is system with inputs and outputs and is composed of many simple and similar processing models. Processing elements have a number of internal parameters called weights. Changing the weights of an element will alter the behavior of the whole network. The goal here is to choose the weights of the network to achieve a desired input/output relationship. This process is known as training the network. [3]

\subsection{Identification of Robot Arm and Magnet}

\section{Levitation Model}

By using identification tool and open loop response of the plant, we can get transfer function for the plant. Base fit for the robot arm plant is 99.03. The transfer function of the robot arm plant is as shown in Eq (5).

$$
G_{1}(s)=\frac{0.006707}{s^{2}+0.5266 s+0.6672} e^{-0.03}
$$

Base fit for magnet levitation plant is 96.88. Tranfer function of magnet levitation plant is as showm in $\mathrm{Eq}$ (6)

$$
G_{2}(s)=\frac{0.02397}{s+0.04456} e^{-1}
$$

\section{AUTO TUNING OF PID CONTROLLER}

\section{Example1:}

Here we can consider robot arm plant with transfer function as obtained in $\mathrm{Eq}$ (5). The simulation diagram for relay tuning of the plant is as shown in fig. 1 .

Relay auto tuning experiment was carried out for different relay heights. The fig (2) shows the relay response for the relay height $h=10$. From the experimental results ultimate gain was calculated. In improved relay tuning method use relay height $\mathrm{h}=18 \& \mathrm{~N}=9$ put this value in Eq (3).In toguchi method expriment is carried out for different values of harmonics. SNR caluculated at each value of harmonics and orthogonal array as shown in table(1). sum of SNR at each height and harmonics caluclated. In this method used relay height $h=10 \& N=7$ shown in table(2). Taguchi gives the optimum value of each parameter with the help of this optimum values we have calculated the ultimate gain and error in calculation of ultimate gain as shown in table(3). Percentage error in calculation of ultimate gain is $17.28 \%$, $1.082 \%, 0.2506 \%$ for conventional , improved relay tuning , taguchi method respectively. The PID tuning paratmeter was calculated using Zigler Nicholus formula as shown in table(4). 


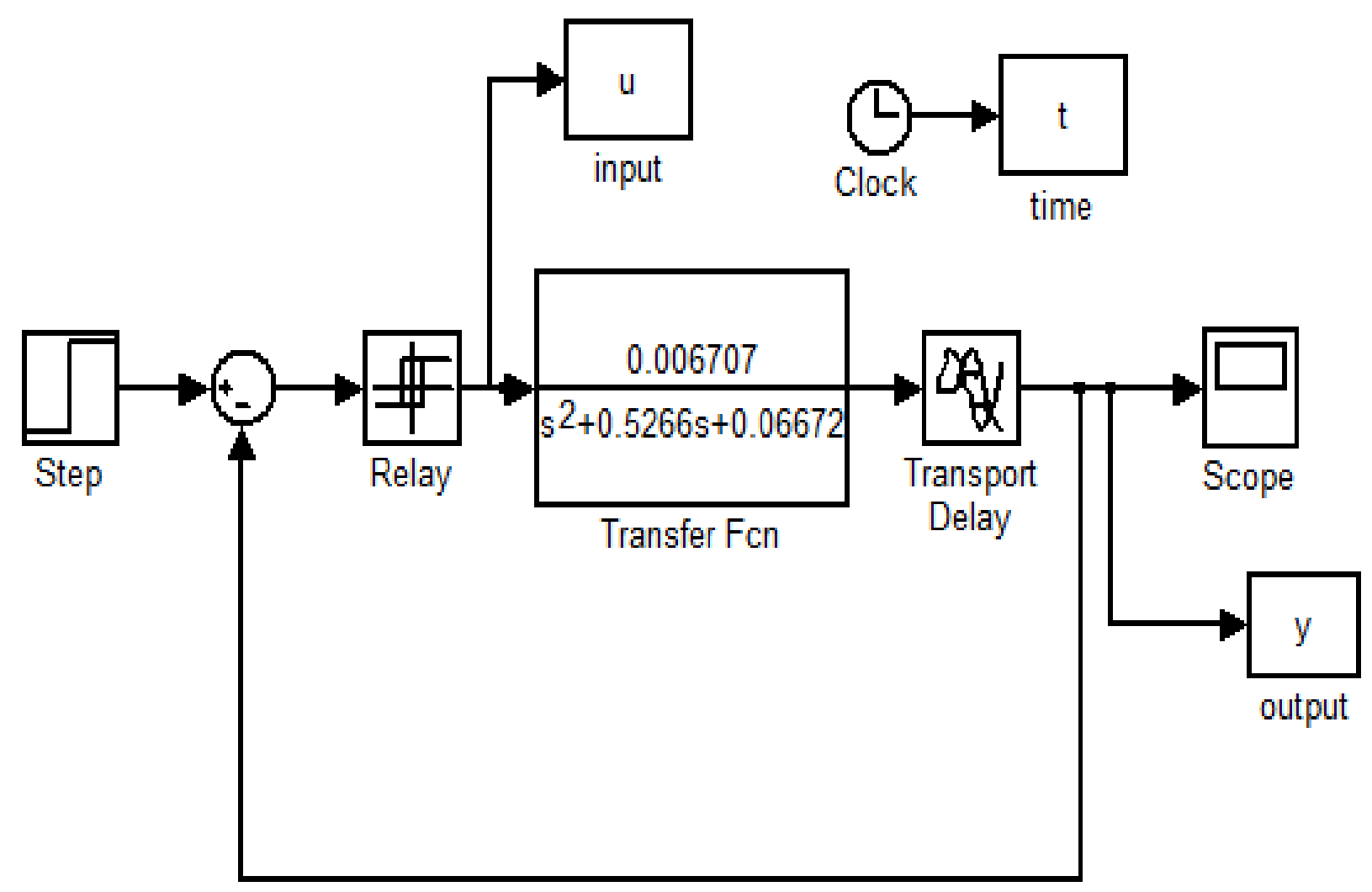

Fig.1: Simulink diagram for robot arm plant
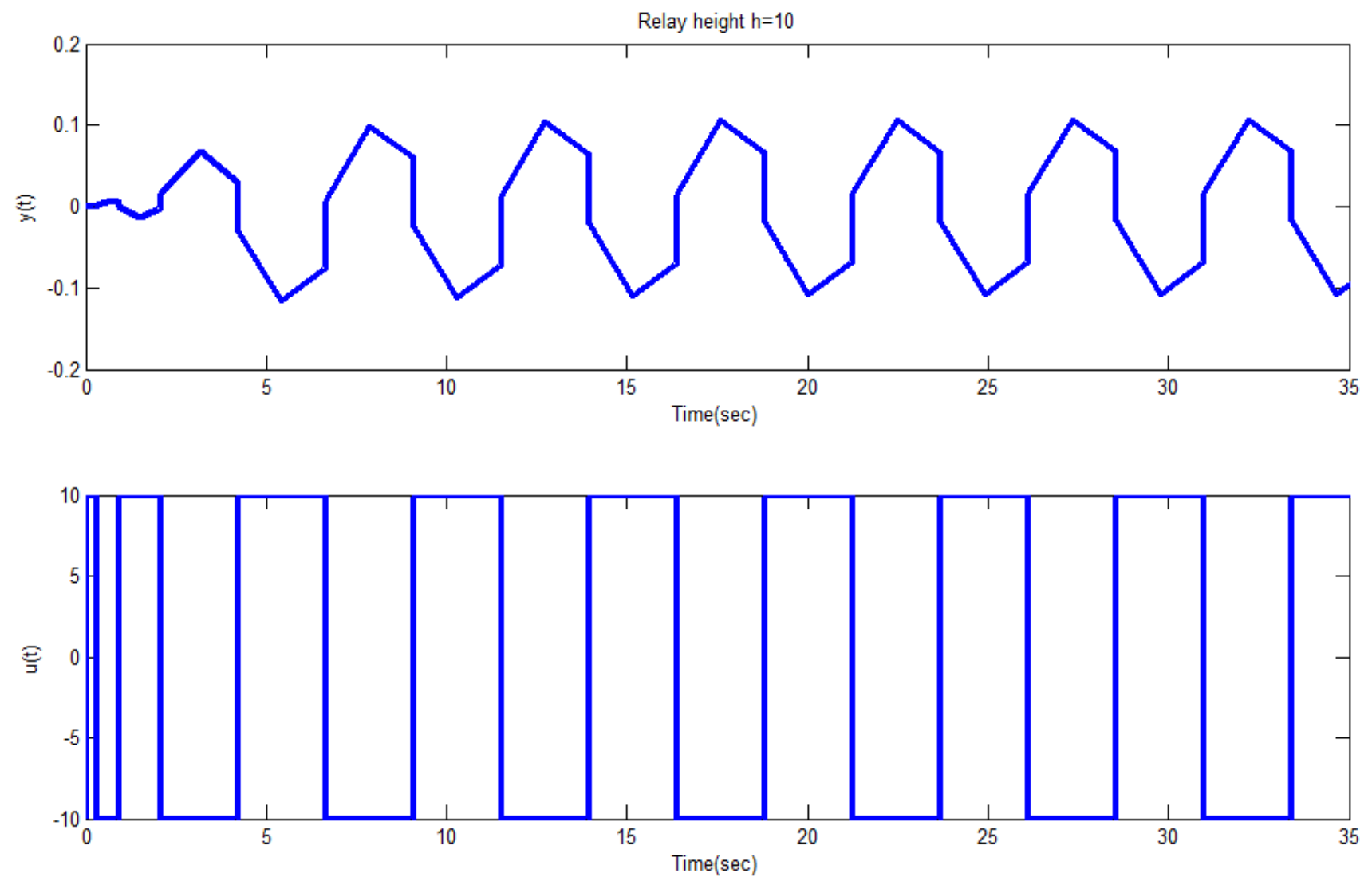

Fig .2: Process and Relay response for Robot Arm Plant. 
Table-1: Taguchi OA for robot arm plant.

\begin{tabular}{|l|l|l|l|l|l|l|}
\hline Sr.No & $\mathbf{h}$ & $\mathbf{N}$ & $\mathbf{K u}(\mathbf{C a l})$. & $\mathbf{K u}(\mathbf{a c t u a l})$ & \% error & SNR \\
\hline 1 & 10 & 1 & 121.34 & 146.9 & 17.46 & 15.911 \\
\hline 2 & 10 & 3 & 135.31 & 146.9 & 7.8 & 22.158 \\
\hline 3 & 10 & 5 & 142.41 & 146.9 & 3.0 & 30.411 \\
\hline 4 & 10 & 7 & 147.28 & 146.9 & 0.25 & 51.744 \\
\hline 5 & 10 & 9 & 151.033 & 146.9 & 2.813 & 31.015 \\
\hline 6 & 12 & 1 & 119.35 & 146.9 & 18.75 & 14.539 \\
\hline 7 & 12 & 3 & 133.21 & 146.9 & 9.31 & 20.621 \\
\hline 8 & 12 & 5 & 140.21 & 146.9 & 4.96 & 26.820 \\
\hline 9 & 12 & 7 & 144.99 & 146.9 & 1.30 & 37.721 \\
\hline 10 & 12 & 9 & 148.68 & 146.9 & -1.211 & 38.332 \\
\hline 11 & 14 & 1 & 119.84 & 146.9 & 18.42 & 14.694 \\
\hline 12 & 14 & 3 & 133.75 & 146.9 & 8.95 & 20.963 \\
\hline 13 & 14 & 5 & 140.76 & 146.9 & 4.17 & 27.597 \\
\hline 14 & 14 & 7 & 145.58 & 146.9 & -0.89 & 40.928 \\
\hline 15 & 14 & 9 & 149.28 & 146.9 & -1.626 & 35.776 \\
\hline 16 & 16 & 1 & 116.44 & 146.9 & 18.69 & 14.567 \\
\hline 17 & 16 & 3 & 133.31 & 146.9 & 9.25 & 20.677 \\
\hline 18 & 16 & 5 & 140.30 & 146.9 & 4.49 & 26.955 \\
\hline 19 & 16 & 7 & 145.10 & 146.9 & 1.22 & 38.272 \\
\hline 20 & 16 & 9 & 149.28 & 146.9 & -1.62 & 37.788 \\
\hline 21 & 18 & 1 & 119.19 & 146.9 & 18.86 & 14.481 \\
\hline 22 & 18 & 3 & 133.04 & 146.9 & 9.43 & 20.509 \\
\hline 23 & 18 & 5 & 140.01 & 146.9 & 4.69 & 26.509 \\
\hline 24 & 18 & 7 & 144.80 & 146.9 & 1.42 & 36.954 \\
\hline 25 & 18 & 9 & 148.49 & 146.9 & -1.082 & 39.312 \\
\hline & & & & &
\end{tabular}

Table 2: Sum of SNR at different levels for relay tuning \begin{tabular}{|l|l|l|l|l|l|l|}
\hline Parameters & L1 & L2 & L3 & L4 & L5 & Total \\
\hline
\end{tabular} \begin{tabular}{|l|l|l|l|l|l|l|l|l|}
\hline Relay height(h) & $\mathbf{1 5 1 . 2}$ & 138.0 & 139.9 & 138.2 & 137 & 708 \\
\hline
\end{tabular} \begin{tabular}{|l|l|l|l|l|l|l|l|}
\hline No. of harmonics (N) & 74.20 & 104.9 & 138.4 & $\mathbf{2 0 5 . 6}$ & 182 & 708 \\
\hline
\end{tabular}

Table-3: Comparison of \% error in $\mathrm{Ku}$ calculation

\begin{tabular}{|l|l|l|l|l|}
\hline $\begin{array}{l}\text { Sr. } \\
\text { No }\end{array}$ & Method & $\begin{array}{l}\text { Ku } \\
(\mathbf{a c t})\end{array}$ & $\begin{array}{l}\text { Ku } \\
\text { (Cal) }\end{array}$ & \%error \\
\hline 1 & Conventional Method & 146.9 & 119.66 & 17.48 \\
\hline 2 & Improved Relay tuning Method & 146.9 & 148.49 & 1.082 \\
\hline 3 & Taguchi Method & 146.9 & 147.28 & 0.2586 \\
\hline
\end{tabular}

Table-4: PID parameters using Ziegler-Nichols settings

\begin{tabular}{|l|l|l|l|l|}
\hline $\begin{array}{l}\text { Sr. } \\
\text { No }\end{array}$ & Method & P & I & D \\
\hline 1 & Conventional Method & 70.3911 & 2.405 & 0.6125 \\
\hline 2 & Improved Relay tuning Method & 87.3470 & 2.405 & 0.6125 \\
\hline 3 & Taguchi Method & 86.635 & 2.405 & 0.6125 \\
\hline
\end{tabular}

\section{Example2:}

Here we can consider magnet levitation plant with transfer function as obtained in $\mathrm{Eq}$ (6). The simulation diagram for relay tuning of the plant is as shown in fig 3 .

In the present work same procedure like example 1 is carried out. In improved relay tuning method, use relay height $\mathrm{h}=25 \& \mathrm{~N}=7$ put this value in $\mathrm{Eq}(3)$.In taguchi method used relay height $\mathrm{h}=10 \& \mathrm{~N}=9$. Percentage error in calculation of ultimate gain is $23.714 \%, 5.97 \%, 3.5733 \%$ for conventional, improved relay tuning, taguchi method respectively shown in table(7). The PID tuning paratmeters was calculated using Zigler Nichols formule as shown in table(8).

Table-5: Taguchi OA for robot arm plant.

\begin{tabular}{|l|l|l|l|l|l|l|}
\hline Sr. No & $\mathbf{h}$ & $\mathbf{N}$ & $\mathbf{K u}(\mathbf{C a l})$ & Ku(actual) & \% error & SNR \\
\hline $\mathbf{1}$ & 5 & 1 & 60.964 & 78.722 & 22.607 & 12.915 \\
\hline $\mathbf{2}$ & 5 & 3 & 68.043 & 78.722 & 13.628 & 17.311 \\
\hline $\mathbf{3}$ & 5 & 5 & 71.609 & 78.722 & 9.0926 & 20.826 \\
\hline $\mathbf{4}$ & 5 & 7 & 74.060 & 78.722 & 5.922 & 24.550 \\
\hline $\mathbf{5}$ & 5 & 9 & 75.944 & 78.722 & 3.5890 & 28.900 \\
\hline $\mathbf{6}$ & 10 & 1 & 60.935 & 78.722 & 22.5943 & 12.920 \\
\hline $\mathbf{7}$ & 10 & 3 & 68.011 & 78.722 & 13.605 & 17.355 \\
\hline $\mathbf{8}$ & 10 & 5 & 71.575 & 78.722 & 9.077 & 20.8411 \\
\hline $\mathbf{9}$ & 10 & 7 & 74.025 & 78.722 & 5.966 & 24.486 \\
\hline $\mathbf{1 0}$ & 10 & 9 & 75.908 & 78.722 & 3.5733 & 29.037 \\
\hline $\mathbf{1 1}$ & 15 & 1 & 60.944 & 78.722 & 22.58 & 12.925 \\
\hline $\mathbf{1 2}$ & 15 & 3 & 68.021 & 78.722 & 13.592 & 17.334 \\
\hline $\mathbf{1 3}$ & 15 & 5 & 71.587 & 78.722 & 9.063 & 20.854 \\
\hline $\mathbf{1 4}$ & 15 & 7 & 74.036 & 78.722 & 5.951 & 24.508 \\
\hline $\mathbf{1 5}$ & 15 & 9 & 75.920 & 78.722 & 3.558 & 28.975 \\
\hline $\mathbf{1 6}$ & 20 & 1 & 60.935 & 78.722 & 22.594 & 12.920 \\
\hline $\mathbf{1 7}$ & 20 & 3 & 68.011 & 78.722 & 13.605 & 17.326 \\
\hline $\mathbf{1 8}$ & 20 & 5 & 71.575 & 78.722 & 9.0778 & 20.840 \\
\hline $\mathbf{1 9}$ & 20 & 7 & 74.025 & 78.722 & 5.9665 & 24.485 \\
\hline $\mathbf{2 0}$ & 20 & 9 & 75.908 & 78.722 & 3.573 & 28.939 \\
\hline $\mathbf{2 1}$ & 25 & 1 & 60.941 & 78.722 & 22.587 & 12.922 \\
\hline $\mathbf{2 2}$ & 25 & 3 & 68.017 & 78.722 & 13.597 & 17.3311 \\
\hline $\mathbf{2 3}$ & 25 & 5 & 71.582 & 78.722 & 9.069 & 20.848 \\
\hline $\mathbf{2 4}$ & 25 & 7 & 74.032 & 78.722 & 5.957 & 24.419 \\
\hline $\mathbf{2 5}$ & 25 & 9 & 75.916 & 78.722 & 3.5643 & 28.960 \\
\hline & & & & & \\
\hline
\end{tabular}

Table-6: Sum of SNR at different levels for relay tuning \begin{tabular}{|l|l|l|l|l|l|l|}
\hline Parameters & L1 & L2 & L3 & L4 & L5 & Total \\
\hline
\end{tabular} \begin{tabular}{|l|l|l|l|l|l|l|l|}
\hline Relay height(h) & 104.5 & $\mathbf{1 0 4 . 6}$ & 104.5 & 104 & 104.2 & 522.4 \\
\hline
\end{tabular} \begin{tabular}{|l|l|l|l|l|l|l|}
\hline No of harmonics $(\mathrm{N})$ & 64.60 & 86.62 & 103.8 & 122 & $\mathbf{1 4 4 . 8}$ & 522.4 \\
\hline
\end{tabular}

Table-7: Comparison of \% error in $\mathrm{Ku}$ calculation

\begin{tabular}{|l|l|l|l|l|}
\hline $\begin{array}{l}\text { Sr. } \\
\text { NO }\end{array}$ & Method & $\begin{array}{l}\text { Ku } \\
(\mathbf{a c t})\end{array}$ & $\begin{array}{l}\text { Ku } \\
(\mathbf{C a l})\end{array}$ & $\mid$ \%error \\
\hline 1 & Conventional method & 78.722 & 60.172 & 23.714 \\
\hline 2 & Improved Relay Method & 78.722 & 74.032 & 5.957 \\
\hline 3 & Taguchi Method & 78.722 & 75.908 & 3.5733 \\
\hline
\end{tabular}

Table-8: PID parameters using Ziegler-Nichols settings

\begin{tabular}{|l|l|l|l|l|}
\hline Sr. No & Method & P & I & D \\
\hline 1 & Conventional Method & 35.3952 & 1.6465 & 0.41162 \\
\hline 2 & Improved Relay tuning & 43.548 & 1.6465 & 0.41162 \\
\hline 3 & Taguchi Method & 45.545 & 1.6465 & 0.41162 \\
\hline
\end{tabular}




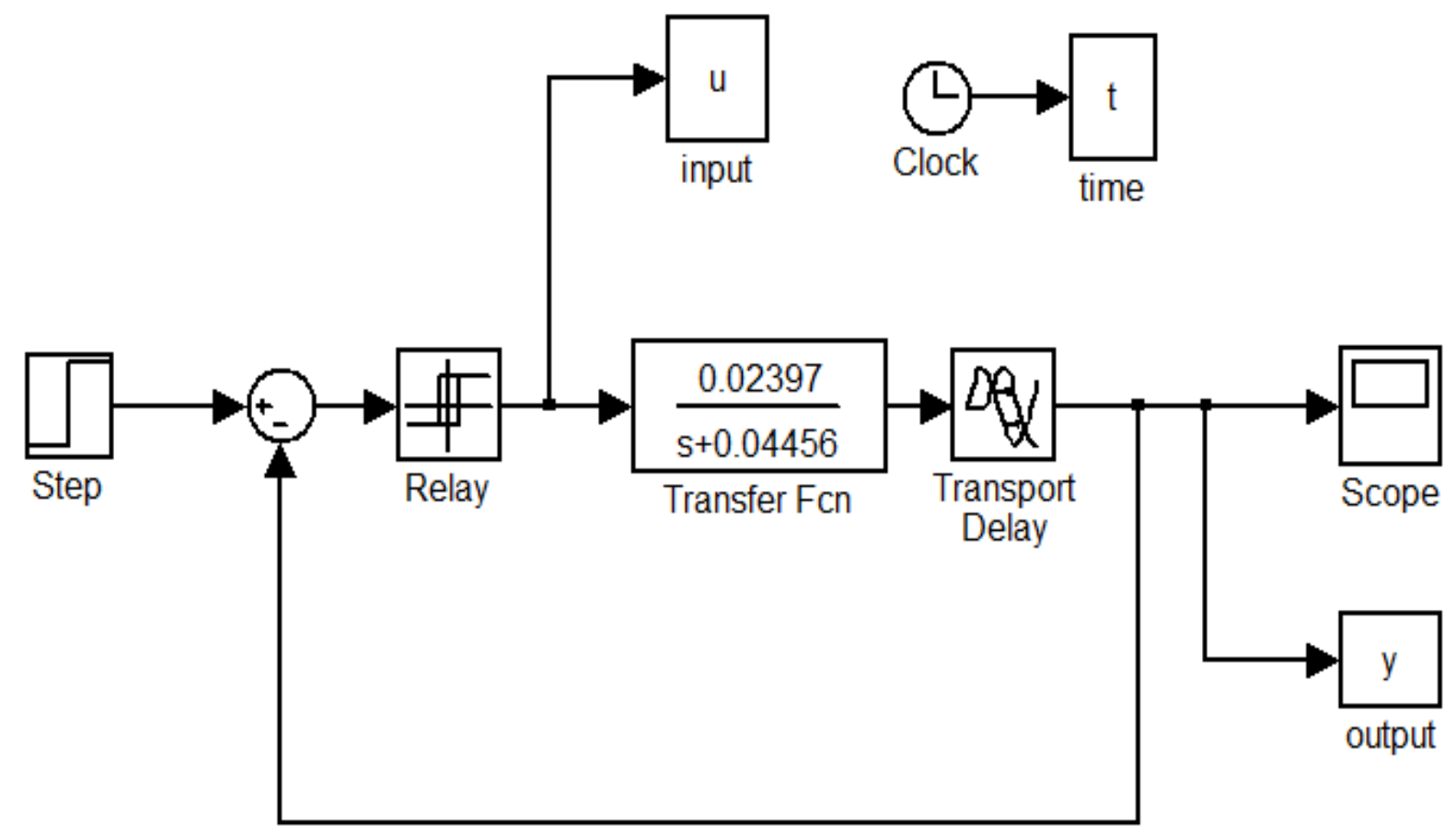

Fig 3: Simulink diagram for magnet levitation plant
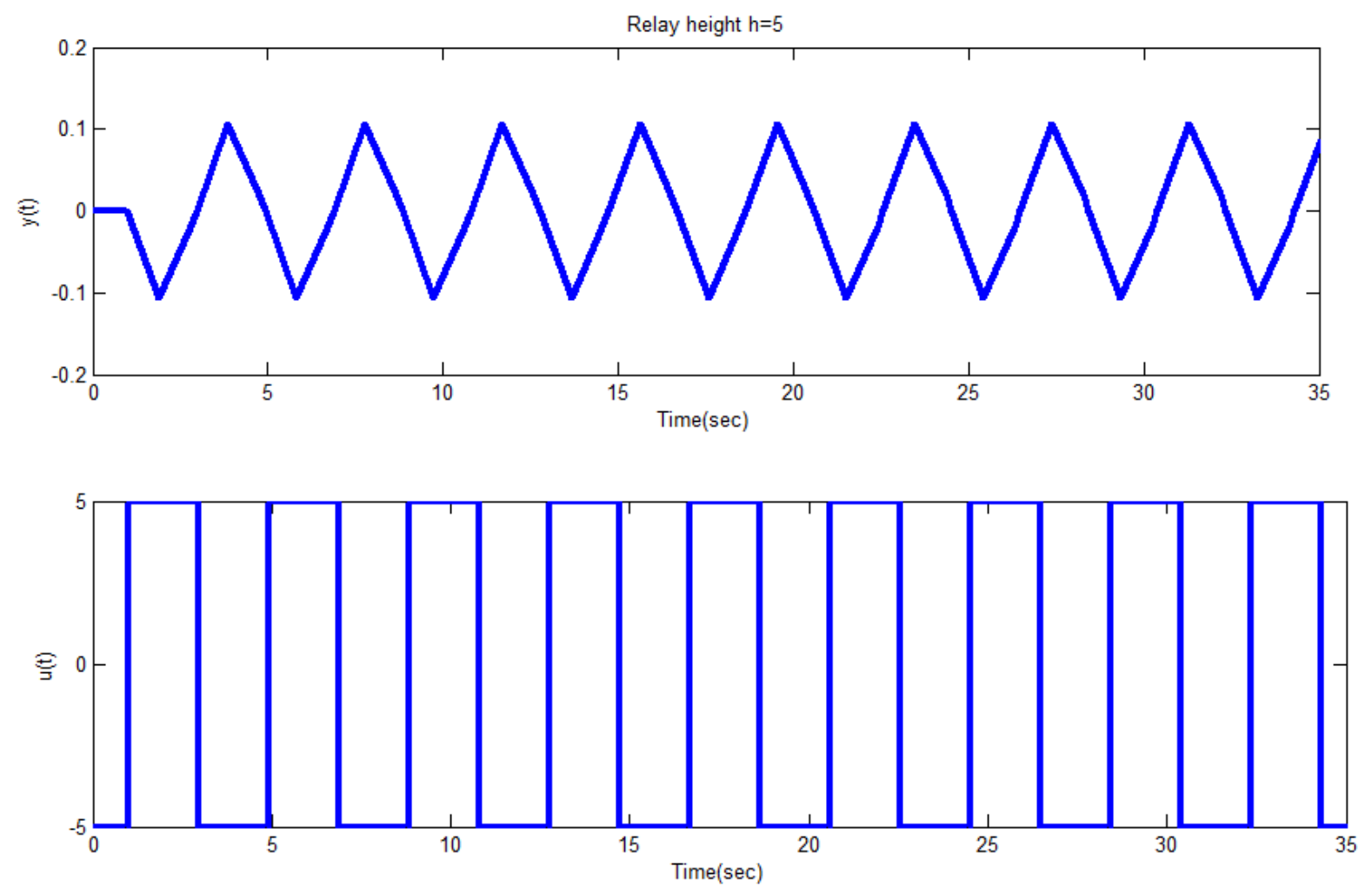

Fig 4: Process and Relay Response for Magnet

\subsection{Artificial Neural Controller Training:}

After the auto tuning of the plants we go through the artificial neural training. At first we train that controller. In this the PID controller replace by artificial neural network controller as shown in fig (5). Once training of that controller is over run that model and get the result. From result we can calculate the integral square error 


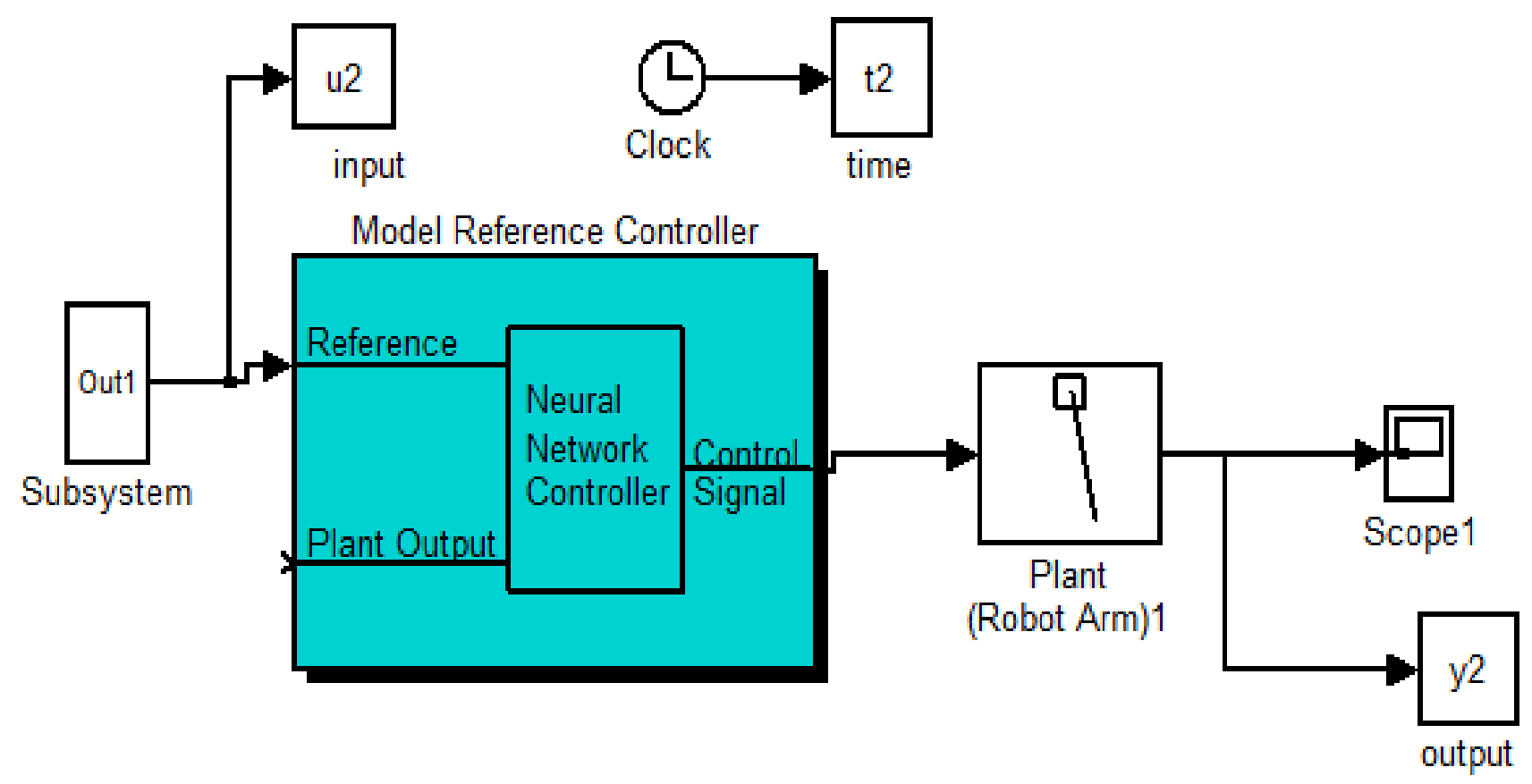

Fig 5: Artificial neural network model for robot arm plant
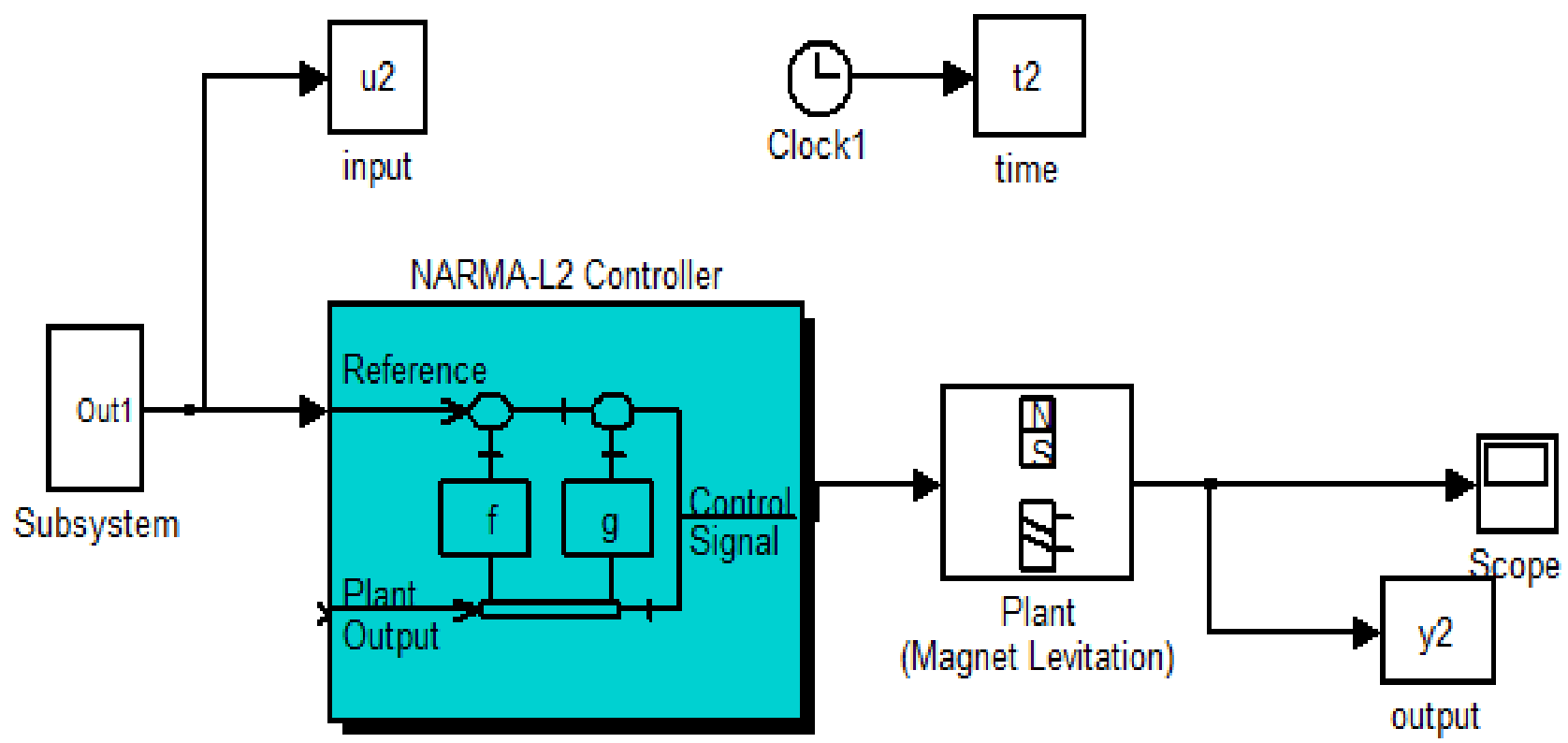

Fig 6: Artificial neural network model for magnet levitation plant

\section{SIMULATION RESULTS}

We obtained the results of artificial neural network and auto tuning in MATLAB Simulink for Robot arm plant and Magnet levitation plant. Step response of Auto tuning and artificial neural network for Robot arm plant on basis of results is shown in fig.(7)

The Integral Square Error (ISE) performance criteria were tested for both Auto tuning and ANN. The ISE values is $0.0024,0.1607$ for Auto tuning and ANN respectively.

Step response of Auto tuning and artificial neural network for magnet levitation plant on basis of results is shown in fig.(8) .The ISE values is $0.9004,1.1371$ for Auto tuning and ANN respectively. 


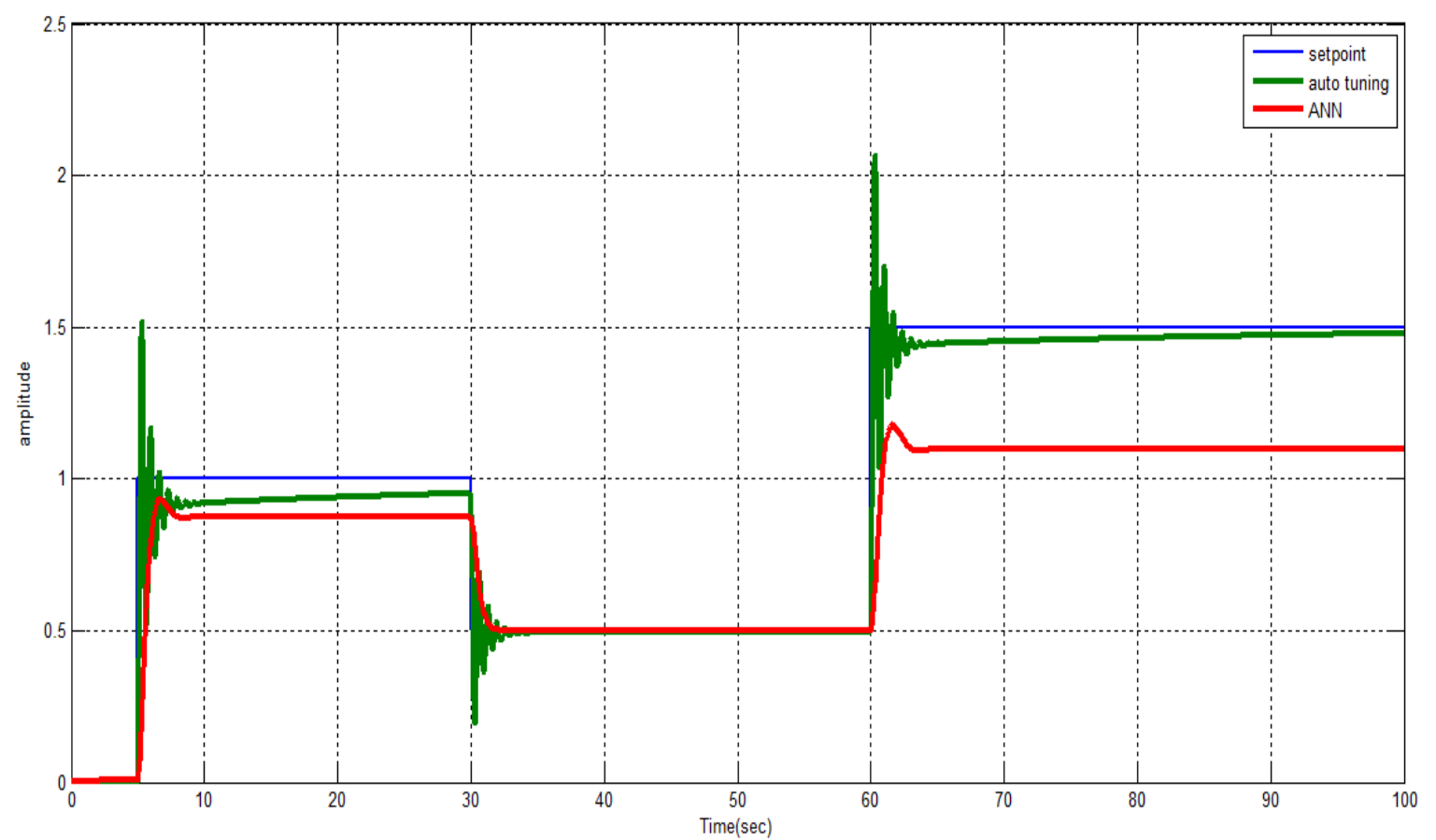

Fig 7: Step response of ANN and auto tuning for Robot arm plant

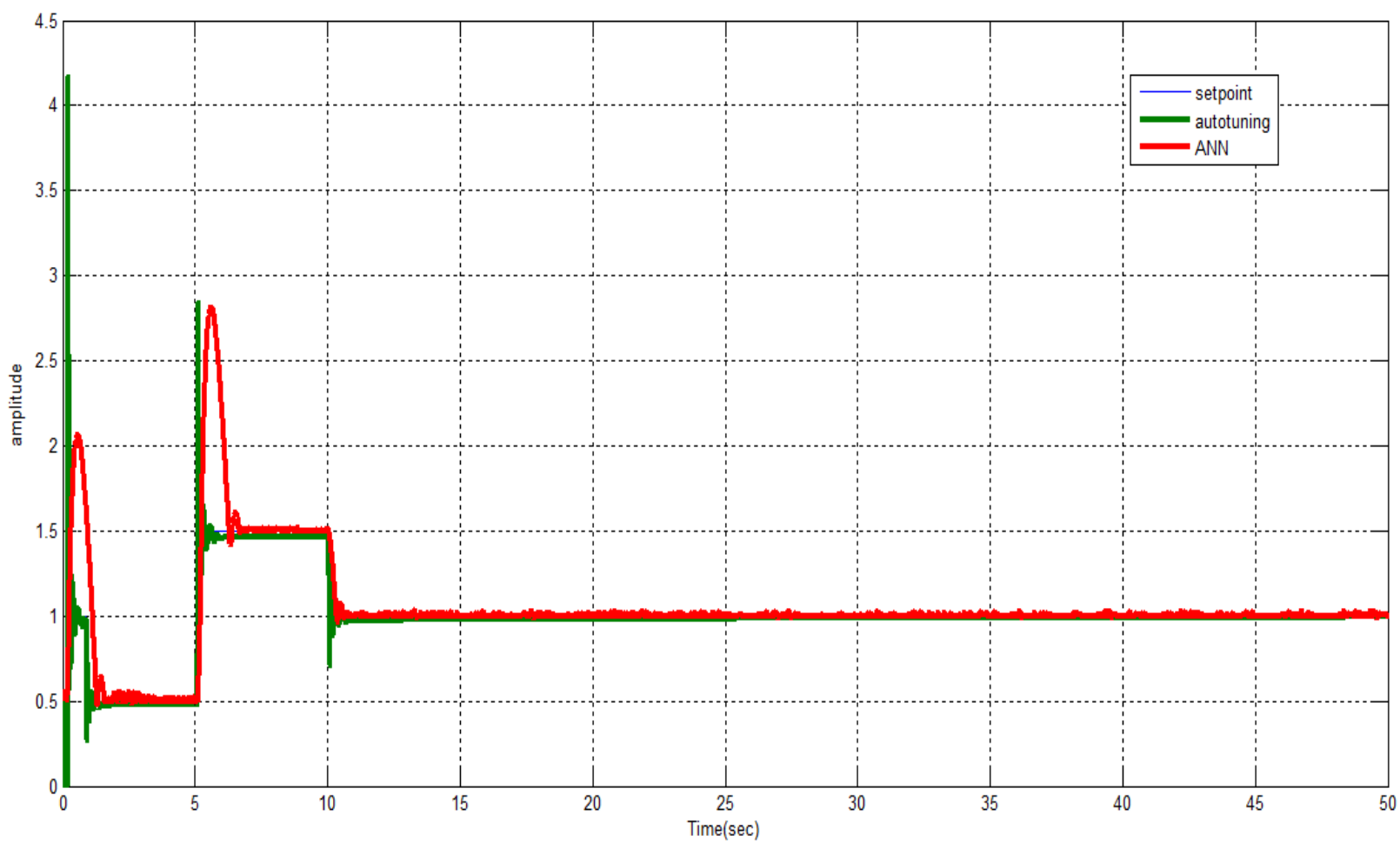

Fig 8: Step response for ANN and auto tuning for Magnet levitation plant

\section{CONCLUSION}

The manual PID tuning method is tedious and time consuming; the resultant system performance mainly depends on the experience and the process knowledge of the engineer. So, goal of present work is to carry out the auto tuning of PID controller using MATLAB Simulink. We obtained ultimate gain and ultimate period by performing relay experiment. Further controller parameters were determined by using Ziegler Nicholas method. The performance of auto tuned PID controller is better than that of artificial neural network. Hence Auto tuning of PID controller plays vital role, especially in the case where large number of controllers is required to be tuned simultaneously. 


\section{REFERENCES}

[1]. Astrom KJ and Hagglund, "Automatic tuning of simple regulators with specification on phase and amplitude margin" (1984).

[2]. S.A. Misal, V.S.sathe, "Application of proposed improved relay tuning for design of optimum PID control of SOPDT model." ARPN journal of system and software.(2012).

[3]. I.J.Nagrath, M.Gopal, "Control system engineering" New Age International Publishers.(2008).

[4]. Byrne, S. Taguchi, "The Taguchi approach to parameter design", Proceeding of the 40th Quality Congress, May 1986, Anaheim, CA., pp.: 168-177. (1986).

[5]. Bequette BW. Process control: Modeling, design, and simulation. Prentice-Hall: Upper Saddle River; (2003).

[6]. Ziegler J. G. Nichols N. B. "Optimum Settings forAutomatic Controllers", Trans. ASME. 65, 433-444. (1942).

[7]. Majhi and Atherton D.P, "On line tuning of controllers for an unstable FOPDT process". IEE proceeding control theory and application.

[8]. Wang Q.G, C.C Huang and B.zou , "A frequency response approach to auto tuning of multivariable control. "Chemical engineering research and design and control". (1997).

[9]. Luyben W.L, "Getting more information from relay feedback test” (2001). 